\title{
Article
}

\section{Initial development of an implicit and explicit approach to assess psychopathy}

Ireland, Jane Louise, Ireland, Carol Ann, Lewis, Michael, Jones, Catherine and Keeley, Samuel Marc

Available at http://clok.uclan.ac.uk/12922/

Ireland, Jane Louise ORCID: 0000-0002-5117-5930, Ireland, Carol Ann ORCID: 0000-0001-7310-2903, Lewis, Michael ORCID: 0000-0001-5567-3569, Jones, Catherine and Keeley, Samuel Marc (2016) Initial development of an implicit and explicit approach to assess psychopathy. International Journal of Law and Psychiatry, 46 (May-Ju). pp. 117-128. ISSN 0160-2527

It is advisable to refer to the publisher's version if you intend to cite from the work. http://dx.doi.org/10.1016/j.ijlp.2016.02.008

For more information about UCLan's research in this area go to http://www.uclan.ac.uk/researchgroups/ and search for < name of research Group>.

For information about Research generally at UCLan please go to http://www.uclan.ac.uk/research/

All outputs in CLoK are protected by Intellectual Property Rights law, including Copyright law. Copyright, IPR and Moral Rights for the works on this site are retained by the individual authors and/or other copyright owners. Terms and conditions for use of this material are defined in the policies page.

\section{CLoK}

Central Lancashire online Knowledge www.clok.uclan.ac.uk

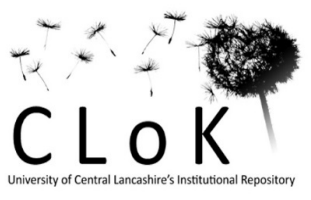




\section{RUNNING TITLE: DEVELOPING A NEW MEASURE OF PSYCHOPATHY}

Initial development of an implicit and explicit approach to assess psychopathy.

Jane L. Ireland*

University of Central Lancashire and Ashworth Research Centre, Mersey Care NHS Trust, UK; Tel: +151 473 0303; Email JLIreland@uclan.ac.uk.

Carol A Ireland,

University of Central Lancashire, Ashworth Research Centre, Mersey Care NHS Trust, UK;

Coastal Child and Adult Therapeutic Services, Poulton le-Flyde, UK; Tel: +151 473 0303;

Email CAIreland@uclan.ac.uk.

Michael Lewis

University of Warwick and Ashworth Research Centre, Mersey Care NHS Trust, UK; Tel: +24 7652 3523; Email: Michael.lewis@warwick.ac.uk.

Catherine Jones,

HM Prison Service; Email: Cat.Jones@hmps.gsi.gov.uk.

Sam Keeley

Coastal Child and Adult Therapeutic Services, Poulton le-Flyde, UK; Tel: +1253 896444

*Correspondence should be addressed to Jane L. Ireland, University of Central Lancashire and Ashworth Research Centre, Mersey Care NHS Trust, UK; TEL: +44 151473 0303; Email: JLIreland1@uclan.ac.uk 


\begin{abstract}
Four studies outline the ACL (Affective, Cognitive and Lifestyle) assessment, a new means of assessing psychopathy capturing implicit and explicit functioning. Studies 1 and 2 comprised students (study 1, $\mathrm{n}=42,14$ men, 28 women; study 2, $\mathrm{n}=50$ men), Study 3 comprised 80 young male prisoners and Study 4, 40 male forensic psychiatric patients. It was predicted that the ACL affective, cognitive and interpersonal components would positively correlate with the interpersonal factor of another measure of psychopathy (PCLSV), whereas the ACL lifestyle component would correlate with the criminal history/lifestyle component of the PCL-SV. Evidence for internal reliability for the ACL was noted. The ACL correlated as expected with the PCL-SV although variation across samples was noted. Implicit affect and specific aspects of cognition positively correlated with increased psychopathy on the PCL-SV. Implicit affect correlated differently across samples. Findings are discussed regarding implications. Directions for future research are indicated.
\end{abstract}

KEY WORDS: Psychopathy; Measure development; Cognition and Affect; ACL 
Initial development of an implicit and explicit approach to assess psychopathy.

Psychopathy as a concept has an interesting history. Originally conceptualised as 'abnormal' personality (Cleckley, 1976) the core traits were described as:

'Superficial charm and good 'intelligence'; absence of delusions or other signs of irrational thinking; absence of 'nervousness' or psychoneurotic manifestations; unreliability; untruthfulness and insincerity; lack of remorse and shame; inadequately motivated antisocial behaviour; poor judgement and failure to learn by experience; pathologic egocentricity and incapacity for love; general poverty in major affective reactions; specific loss of insight; unresponsiveness in general interpersonal relations; fantastic and uninviting behaviour with drink and sometimes without; suicide rarely carried out; sex life impersonal, trivial, and poorly integrated; and a failure to follow any life plan” (Cleckley, 1982, p. 204).

Psychopathy was not originally conceptualised as synonymous with criminal behaviour (Cleckley, 1982) although its perception as 'criminal' personality became a later focus of the most widely utilised assessments of psychopathy (i.e. Psychopathy Checklist, PCL: Hare, 1991). The focus on criminal personality has been criticised by researchers and clinicians who argue that it has served to move the definition of psychopathy towards a moral construct and away from the personality literature (Blackburn, 2007; Cooke \& Michie, 2001).

Nevertheless the PCL and its variations (e.g. PCL-R, PCL-SV, and PCL-YV) remain the primary means of assessing psychopathy. It separates the concept into two core factors; interpersonal [personality] and criminal history/lifestyle. This approach has been criticised for failing to weigh the personality component more than the behavioural component (Cooke \& Michie, 1997). This has led to debate and a developing consensus that psychopathy could be separated into more than the original two factors presented by the PCL. 
A three factor model of psychopathy was proposed by Cooke and Michie (2001) which comprised arrogant and deceitful interpersonal style; deficient affective experience; and an impulsive and irresponsible behavioural style. This model reduced the emphasis on criminal behaviour and raised the importance of affect. Hare (2003) challenged this by presenting a revised four factor (or 'facet') conceptualisation which comprised Interpersonal, Affective, Lifestyle; and Antisocial components. The first three factors were identical to those proposed by Cooke and Michie (2001), with the addition of antisocial. This was followed further by Neumann, Kosson, Forth and Hare (2006) who argued that the three factor solution of Cooke and Michie (2001) was incorrectly presented and analysed and had removed some criminal history/lifestyle items without justification.

Disagreement regarding what factors comprise psychopathy continues. Resolution is unlikely in the immediate future, particularly since support for both sets of factors have been found across community (e.g. Sevecke, Pukrop, Kosson \& Krischer, 2009), psychiatric (e.g. Vitacco, Neumann \& Jackson, 2005), and forensic samples (e.g. Johansson, Andershed, Kerr \& Lavander, 2002; Neumann, Hare \& Johansson, 2013). There is also a danger that research may be moving towards a focus on methodological and conceptual issues relating to the dominating measures of psychopathy (i.e. the PCL) as opposed to revisiting the original conceptualisation of psychopathy. Thus, research appears to have become focused on the measures used and not the original construct. Hare and his colleagues have certainly made a prolific contribution to the field which has stimulated these important debates and moved the concept of psychopathy from a topic of rather minor psychiatric interest to a significant factor influencing clinical and research practice, particularly in the area of risk assessment. Despite this there remains a need to revisit the conceptualisation of psychopathy regarding its measurement and original conceptualisation (Blackburn, 2007; Skeem \& Cooke, 2010). 
Researchers have attempted to develop other means of assessing psychopathy. These include self-report measures (e.g. Levenson Self-Report Psychopathy Scale, Levenson, Kiehl \& Fitzpatrick, 1995; Self-Report Psychopathy Scale, Hare, 1985; Psychopathic Personality Inventory, Lilienfeld \& Andrews, 1996; Elemental Psychopathy Assessment, Lynam et al, 2011; Triarchic Psychopathy Measure, Patrick, 2010), observational approaches (Interpersonal Measure of Psychopathy, Kosson, Steuerwald, Forth \& Kirkhart, 1997; Psychopathy Q-Sort Prototype, Reise \& Oliver, 1994), and interviews assessing dynamic change and incorporating staff ratings (Comprehensive Assessment of Psychopathic Personality [CAPP], Cooke, Hart, Logan \& Michie, 2004). All have focused on explicit assessment, including assessment of explicit behaviour (i.e. observations) as opposed to any attempt at incorporating implicit assessments of functioning, an issue that will be outlined later. Furthermore, only the PCL family of measures and the CAPP combine methods to reach a judgement on the presence of psychopathy (e.g. interviews, collateral information). Even these do not account for implicit approaches, adopting instead a more traditional approach to assessment focused on standard interview-based methods common to clinical assessment measures for related areas, such as personality disorder (e.g. the International Personality Disorder Examination, Loranger, Janca \& Sartorius, 1997).

Furthermore, the significant contribution of the work of Hare has inadvertently led to difficulties in how we revisit the definition of psychopathy. For example, using 'expert' [academic and practitioner] views on defining psychopathy has led to experts simply representing the PCL criteria as opposed to generating new elements or questioning existing elements (Kreis, Cooke, Michie, Hoff \& Logan, 2012). Although it could be argued that this is a product of the PCL capturing all important aspects of the disorder it is equally possible that experts are simply suggesting the PCL criteria due to its salience in the field. There appears empirical basis to question the extent to which such measures capture all aspects of 
psychopathy when it is noted how important elements continue to be neglected by assessment measures. Affect and cognition, for example, are considered integral to the definition of psychopathy (Cleckley, 1976) and yet are not comprehensively captured in measures. This is most marked for cognition.

Attempts to capture affect are evidenced in measures such as the PCL (Hare, 2003) and CAPP (Cooke et al, 2004) but only at a basic and explicit level, with the PCL not covering cognition in any detail. There are certainly no assessments in existence which examine cognition and affect implicitly. There also remains a tendency to examine affect and cognition as correlates of psychopathy and not as integral elements of the disorder.

Regarding cognition there is a general consensus that the following elements are components of psychopathy: 1.) biased expectations of others and the world. This includes in particular a tendency towards hostile beliefs or schema, in keeping with the CognitiveInterpersonal Theory of Psychopathy where those with psychopathy will act in a manner which will produce a negative reaction in others, thus confirming their cognitive bias (Blackburn, 2003); 2.) information processing difficulties (Wallace, Schmitt, Vitale \& Newman, 2000) which include difficulties in anticipating, attending to and appreciating consequences (Blair, Mitchell \& Blair, 2005; Newman, Schmitt \& Voss, 1997; Wallace, Schmitt, Vitale \& Newman, 2000), with evidence for a hostile attribution bias (Vitale et al, 2005); 3.) impulsive responding (Blair et al, 2005) and 4.) moral reasoning/moral cognition difficulties which include inferior moral reasoning (Glenn et al, 2009; O’Kane, Fawcett \& Blackburn, 1996; Young et al, 2012), being unable to distinguish between moral and conventional reasoning, making less reference to the victim's welfare when judging moral situations (Blair, 1995; Blair et al, 1995), and a tendency to make unethical judgements (Stevens et al, 2012). 
Regarding affect, the following elements are considered core to psychopathy: 1.) poverty of major affective reactions including a lack of guilt/remorse and incapacity for affectional bonds (Cleckley, 1982); 2.) general affective deficits (Hastings et al, 2008; Dawel et al, 2012) including poor emotional recognition (Blair, 1995; Blair et al, 2005) which extends to reduced levels of anxiety/fear, sensitivity to punishment (Lykken, 1957; Newman, MacCoon, Vaughn \& Sadeh, 2005) and a reduced ability to recognise some negative emotions, such as fear and sadness (Blair et al, 2004; Montagne et al, 2005). This also includes the misidentification of anger (Iria et al, 2012) and an absence of moral emotion (Blair et al. 2005); 3.) difficulties in evaluating emotion (Cleckley, 1976) and in responding appropriately to these (Lorenz \& Newman, 2002) and 4.) difficulties in attending to emotion correctly (Glass \& Newman, 2009; Baskin-Sommerset al, 2013).

This serves to illustrate the complexity of the area and the range of factors requiring attention. However, focus has centred on the definition and correlates of psychopathy and not on how these factors can be incorporated more comprehensively into assessments. There has been limited innovation regarding how the assessment of a behaviour as complex as psychopathy can be assessed, with focus instead on refining existing traditional and more explicit means of assessment. Much could have perhaps been taken from the field of ability assessment where focus has been on the provision of varied assessments for complex aspects of presentation which serve to minimise social desirability effects, test for transparency and incorporate implicit assessment. Tests such as the Weschler Adult Intelligence Scale (WAISIV: Weschler, 2008) and various tests for dysexecutive functioning (e.g. BADS, Wilson et al, 1996; CogAT, Loham \& Hagen, 2001) are good examples of this.

Connected to this, implicit processing represents an important component to capture. This has been referred to as automatic processing and explores associations in memory that become spontaneously activated under various conditions (Stacy \& Wiers, 2010), with no or 
reduced demands on cognitive effort (De Houwer, Teige-Mocigemba, Spruyt \& Moors, 2009; Ireland \& Adams, in press). Implicit processing tendencies are considered dispositional (Bluemke, Friedrich \& Zumbach, 2009) and hard to fake. They become of direct relevance therefore to assessments of psychopathy where deception and social desirable responding are elevated (Snowden, Gray, Smith, Morris \& MacCulloch, 2004), demanding a need for a range of approaches to be adopted. Implicit testing has also explored cognition and affect in considerable detail (Back, Schmukle \& Egloff, 2009; Stacy \&Wiers, 2010; Ireland \& Birch, 2013) which further supports its relevance to measures of psychopathy where the importance of accounting for cognition and affect more is indicated, and certainly beyond explicit assessment alone.

The distinction between explicit and implicit processing is captured well by the Reflection-Impulsive Model (RIM: Strack \& Deutsch, 2004) which describes an associative system and a reflective system, both of which could co-exist. The reflective system is more consistent with the use of explicit methods of assessment which involves conscious deliberation and appraisal (Hofmann \& Friese, 2008), whereas the associative system is the implicit element. We would argue that assessments of psychopathy have not yet captured the associative (implicit) system and instead have focused on explicit methods of assessment. This is surprising when you consider other areas of research where problematic behaviour has been examined, particularly that susceptible to social desirable responding (e.g. aggression, racism) and where the use of associative/implicit testing is becoming more utilised (e.g. Implicit Association Test, Greenwald, McGhee \& Schwartz, 1998; primed Stroop tests, Stewart, Hall, Wilkie \& Birch, 2002; word association and word production tests, Cramer, 1968, Zeelenberg, Shiffrin \& Raaijmakers, 1999).

Thus, there appear two core areas that measures of psychopathy need to attend to the content of what they are measuring (i.e. the definition of psychopathy) and the process by 
which information is collected (e.g. explicit assessments, implicit assessments, self-report, observational data, collateral/file/third party information). Although there has been considerable debate over content, researchers do not appear to have focused as much attention on process and how this can be combined with content to produce an assessment of psychopathy. The measurement of psychopathy is as important as its definition. The current paper aims to describe an approach to assessing psychopathy that captures both definitional and measurement issues in determining its potential utility. It also aims to move away from merely presenting a 'diagnosis' of psychopathy to exploring instead the specific affective, cognitive and lifestyle functioning challenges evidenced. Such an approach has the potential for providing a more detailed formulation of difficulties and assisting with individualised treatment planning as opposed to relying on a conclusion of psychopathic or nonpsychopathic.

To achieve this, the current paper presents four independent studies examining the content and validity of a new approach, the ACL (Affective, Cognitive and Lifestyle) assessment, which utilises both student and forensic samples. The ACL combines an interview with a self-report measure, collateral information, observation and implicit testing. The first study presents an initial check on the administration and content elements of the ACL using a student sample before proceeding to study two where its validity alongside another other measure of psychopathy (the PCL-SV) is examined. The ensuing two studies repeat this but for specialist samples and incorporating a collateral information element; study three examines the administration and content with a sample of prisoners, before progressing onto study 4 which examines the ACL in a secure psychiatric sample. 


\section{Study 1}

Participants

Forty-two students took part in the initial study (14 men and 28 women). The average age was $24.9(S D=7.5)$. Response rate was 93 per cent.

\section{Overview}

This study aimed to pilot the ACL for utility and to examine its basic reliability in a non-clinical sample. Focus was thus on administration and reliability of the ACL and its subscales, before proceeding onto Study 2 .

\section{Measure}

The ACL (Affective, Cognitive and Lifestyle assessment: Ireland \& Ireland, 2012) was developed following a thematic review of the literature concerning the nature and correlates of psychopathy and methods of measurement. This was completed to avoid any potential for a simple replication of the PCL-R criteria, a problem noted by those utilising alternative methods to develop assessments of psychopathy (e.g. Delphi assessments that use 'experts' to develop; Cooke et al, 2004). The aim was also to capture both the original conceptualisation of psychopathy by Cleckley (1982) as well as accounting for factors included in validated clinical assessment methods for psychopathy (e.g. Hare, 1991; PCL). The review identified four main domains of functioning for consideration: Affective; Cognition; Lifestyle [Behaviour]; and Interpersonal Style. The ACL was consequently structured around these four main domains, with focus on elements within these domains considered associated with raised levels of psychopathy.

Regarding process, the ACL captured both implicit and explicit processing. It utilised a standard structured interview, incorporation of a self-report measure, use of collateral 
information and observational data. Such methods were apparent across the literature but had not previously been combined into a single assessment approach. The implicit components included scenarios for completion by participants and timed testing. The ACL also incorporated a genogram informed approach (e.g. Butler, 2008) to examining relationship quality and quantity.

Thus, focus was on the process of the ACL as much as the content, with the aim to develop an approach to assessment that would be engaging for clients to complete and pragmatic for practitioners to administer. The ACL was not designed to represent a replication or replacement of the PCL but rather as an alternative assessment approach that captured in more detail cognition and affect, incorporating both explicit and implicit processing. The aim was to develop an approach to assessment that was sensitive to the heterogeneity within psychopathy.

The themes identified from the literature regarding content and method elements of the ACL are indicated in Table 1. There were seven themes rated in accordance with the Affective domain, six for the Cognitive domain, 11 for the Lifestyle domain and nine for the Interpersonal domain. Each theme was rated on an overall scale of 0 (no problem) to 3 (extreme problem) for ease of initial administration and to offer some standardisation in the approach across initial validation studies (see Table 1).

<Insert Table 1 here>

Study 1 examines all elements required to complete the ACL, aside from collateral information. This was the focus of the last two studies that used forensic samples. Collateral information was unavailable for student samples. The current study was also focused on the administration elements of the ACL to determine its usability. 
Method

Students were invited to take part in the ACL interview. This lasted approximately 1 to 1.5 hours. All interviews were conducted individually in a private room. The ACL was administered by a single interviewer (SK) trained in its conductance by the authors who designed the initial ACL (JI and CI). The administrator completed practice interviews prior to formal administration. Scoring of individual items of the ACL was completed post all interviews. The authors of the ACL (CI and JI) did not participate in the scoring to maintain independence.

Results

Regarding reliability, the overall ACL total produced an $\alpha$ of .87 ( $n=42,33$ items). Only one item negatively correlated (31: tendency towards narcissism). Removal of this item did not, however, impact on the coefficient. Coefficients were also computed on all component scores. For ACL Affective this produced an $\alpha=.67(\mathrm{n}=42,7$ items), with no negative inter-item correlations. For ACL Cognitive, $\alpha=.58(n=42,6$ items $)$, with one item negatively correlating (3I: tendency towards narcissism). With this item removed the coefficient increased to .66. ACL Lifestyle produced an $\alpha$ of $.71(\mathrm{n}=42,11$ items), with ACL Interpersonal producing an $\alpha$ of .70 ( $n=42,9$ items). There were no negatively correlating items on either scale.

Means across the total ACL and its component elements are indicated in Table 2. <Insert Table 2 here>

There were no differences across sex in relation to the Affective $(F=1.01 \mathrm{~ns})$, Cognitive $(F=.13 \mathrm{~ns})$, Lifestyle $(F=.02 \mathrm{~ns})$ or Interpersonal $(F=.51 \mathrm{~ns})$ components. There was no sex difference on the ACL total $(F=.07 \mathrm{~ns})$. 
Correlations were computed between the component elements of the ACL; Affective correlated positively with all components (Cognitive $\mathrm{r}=.52, p=.001$; Lifestyle, $\mathrm{r}=.50, p=$ .001 ; Interpersonal style, $\mathrm{r}=.48, p=.001)$; Cognitive positively correlated with the remaining components (Lifestyle, $\mathrm{r}=.64, p=.001$; Interpersonal style, $\mathrm{r}=.64, p=.001$ ); Lifestyle and Interpersonal also positively correlated $(\mathrm{r}=.57, p=.001)$. All components of the ACL correlated highly with the total score (Cognitive, $\mathrm{r}=.85, p=.001$; Affective, $\mathrm{r}=.74$, $p=.001$; Lifestyle, $\mathrm{r}=.85, p=.001$; Interpersonal style, $\mathrm{r}=.81, p=.001$ ).

\section{Discussion}

This initial reliability study provided evidence for internal reliability. Only one item negatively correlated (3I: tendency towards narcissism) but this did not impact on overall reliability, although it did on the component score. It is also accepted that some of the coefficients considered moderate in size were a likely result of a small number of items within each component. Regarding component elements, all correlated similarly with the total ACL score which confirmed internal composition further. There were also no difficulties reported with the administration of the measure. The small sample size and divergence in sex ratio is acknowledged, with the aim of the current study simply a basic reliability assessment before proceeding onto a more detailed analysis of the ACL's performance alongside a well established measure of psychopathy. Nevertheless, accounting for initial positive signs of reliability and administration of the ACL it was felt possible to proceed with a more detailed analysis in the ensuing study, focusing on aspects of validity. 


\section{Study 2}

Participants

Fifty male students took park. The average age was 22.5 (sd 4.43). Response rate was 96 per cent.

Overview

Study two aimed to gather further information on the reliability of the ACL, extending this to exploring its relationship with an existing measure of psychopathy to determine concurrent validity and discriminant reliability for some of the component scores. It was predicted that the ACL would positively correlate with an existing measure of psychopathy, the PCL-SV. In addition, it was predicted that the affective, cognitive and interpersonal components of the ACL would positively correlate with Factor 1 of the PCL-SV, and the Lifestyle component of the ACL with Factor 2 of the PCL-SV. Finally, it was also predicted that the implicit elements of the ACL, namely implicit affect and cognitive elements, would be positively associated with the personality component of psychopathy (i.e. Factor 1 PCLSV) and not the behavioural component (i.e. Factor 2 PCL-SV) since implicit affect and cognition are argued to be more closely associated with personality factors.

\section{Measure}

The ACL was employed in the current study as for study 1 (see Table 1). In addition, the PCL-SV (Hart, Cox \& Hare, 1995) was employed. This is a 20 item checklist for assessing psychopathy that has been validated for use with both community and forensic samples. It gathers information using an interview and, if available, collateral information. It comprises two factors; Factor 1 interpersonal (personality) style and Factor 2 criminal history and lifestyle. As for Study 1, collateral information was not utilised to support the measure 
completion since the study was accessing a student sample for which collateral information was unavailable.

The current study also examined the implicit testing element of the ACL in more detail via the four implicit sets of such tests within the ACL, two examining emotion and two examining cognition as follows:

Implicit Emotion 1: Identification (1E). The number of correctly identified emotional words assessed via three scenarios, also incorporating response time;

Implicit Emotion 2: Feeling (1F). Ability to feel emotions where participants are asked to rank correctly seven emotion inducing event scenarios (scenarios based on true events). This incorporates response time and two measures of empathy, i.e. how much the scenarios produce emotion in them and how much they would produce emotion in others;

Implicit Cognition 1: Moral Judgements (2C). Making moral judgements using three scenarios, including the percentage likelihood of selecting a higher conventional reasoning response, the number of reasons generated and response time;

Implicit Cognition 2: Conditional reasoning - Hostile Responding (2D). Participants are presented with ten scenarios and asked to select their preferred responses from a series of logical and illogical responses. It allows for a total hostility score to be indicated.

Method

Students were invited to take part in the ACL and PCL-SV interview simultaneously. Each combined interview lasted approximately 1.5 to 2 hours. A small honorarium was provided to participants to reimburse them for their time. All interviews were conducted individually in a private room. The ACL was administered by a single interviewer (ML) trained by the ACL authors. Practice interviews were completed prior to formal administration. Scoring of the measures were completed post interviews so that the results of 
one measure (ACL) did not inform the results of the other (PCL-SV). Again, the authors of the ACL (CI and JI) did not participate in the scoring to maintain independence.

Results

Alpha coefficients were calculated across all measures and component scores, with the following results; ACL total $\alpha=.88(\mathrm{n}=50,33$ items). Only one item negatively correlated (41: Impulsivity, part of Interpersonal Style) but removal of this had no appreciable impact on the coefficient; ACL Affective $\alpha=.72(\mathrm{n}=50,7$ items $)$; ACL Cognitive, $\alpha=.60(n=50,6$ items); ACL Lifestyle produced an $\alpha$ of $.76(n=50,11$ items); ACL Interpersonal, $\alpha$ of $.69(n=50,9$ items). Removal of the implicit items from the Affective and Cognitive components did not impact on the reliability of Affective ( $\alpha$ remained .76) but slightly worsened the alpha for Cognitive $(\alpha=.53)$. Regarding the PCLSV, reliabilities were as follows: PCL-Total, $\alpha$ of $.83(n=50,12$ items); PCL-SV Factor $1, \alpha$ of $.83(n=50,6$ items $)$ and PCL-SV Factor 2, $\alpha$ of $.59(n=50,6$ items $)$. No items negatively correlated across any scales (ACL or PCL-SV).

Means across the total ACL and PCL-SV and their respective component elements are indicated in Table 2.

<Insert Table 2 here>

Correlations were also computed between the ACL and PCL-SV. Total ACL scores and total PCL-SV scores were positively correlated $(r=.88, \mathrm{n}=50, p=.001)$, as were ACL total scores and Factor 1 and 2 of the PCL-SV $(r=.78, p=.001$ and $r=.62, p .001$ respectively). Regarding ACL components, the PCL-SV total correlated positively with all components; Cognitive, $r=.65 p=.001$; Affective, $r=.81, p=.001$; Interpersonal, $r=.58, p$ $=.001 ;$ Lifestyle, $r=.85, p=.001$. 
Across PCL-SV factors, Factor 1 (interpersonal) correlated positively with all ACL components; Cognitive, $r=.62 p=.001$; Affective, $r=.71, p=.001$; Interpersonal, $r=.65, p$ $=.001$; Lifestyle $r=.67, p=.001$. Factor 2 (criminal history and lifestyle) correlated positively with Cognitive, $r=.39, p=.004$; Affective, $r=.58, p=.001$ and Lifestyle, $r=.73$, $p=.001$, but not with Interpersonal $(r=.20 \mathrm{~ns})$.

\section{Implicit components of the ACL: Association with PCL-SV}

The implicit emotion elements of the ACL (IE - identifying emotions; $1 \mathrm{~F}$ - feeling emotions) correlated positively, albeit not highly, with the PCL-SV total (IE: $r=.36 p=.009$; IF: $r=.39 p=.005)$, and PCL-SV Factor 1 (IE: $r=.40, p=.004$; IF: $r=.40, p=.001)$ but not with PCL-SV Factor 2 (IE: $r=.32 \mathrm{~ns}$; IF: $r=.45 \mathrm{~ns}$ ). The implicit cognitive elements only correlated positively (and again not highly) with the PCL-SV total in relation to conditional [hostile] reasoning (2D: $r=.36 p=.01)$ and not in relation to moral reasoning $(r=.18 \mathrm{~ns})$. Across the PCL-SV subscales, implicit cognition correlated with Factor 1 (2C: $r=.31, p$ $=.02 ; 2 \mathrm{D}: r=.40, p=.004)$ but not with PCL-SV Factor $2(2 \mathrm{C}: r=-.09 \mathrm{~ns} ; 2 \mathrm{D}: r=.14 \mathrm{~ns})$.

The four implicit sets of tests within the ACL (i.e. response time; individual elements comprising each test) were examined in more detail. These tests could be analysed separately from the overall rating used to denote the ACL item scores for IE, 1F, 2C, 2D. This allowed them to be compared to the overall ACL total as well as the PCL-SV. These results are presented in Table 3.

<Insert Table 3 here>

As psychopathy scores increased on the PCL-SV the number of correctly identified emotional words decreased, with this holding across PCL-SV Factor 1 (interpersonal) but not Factor 2. There was a trend for the same pattern associated with higher total ACL scores.

As psychopathy scores increased on the PCL-SV and the ACL the ability to acknowledge personal emotions invoked decreased, with this also holding across Factor 1 
(interpersonal) scores on the PCL-SV but not Factor 2. The ability to identify emotions in others and to correctly rank responses was not associated.

The tendency to give a conventionally moral response was not associated with the PCL-SV or its factor scores although there was a negative correlation with total ACL indicating that increased moral scores were associated with decreased levels of overall psychopathy. However, the reasoning component of moral reasoning did appear to relate to psychopathy levels, both with the ACL and the PCL, with decreased reasoning ability associated with increased total ACL and PCL-SV scores, and increased PCL-SV Factor 2 scores.

Across all measures response time was not associating with the psychopathy total or subscale scores. Conditional reasoning was also failing to associate.

Discussion

Convergence was indicated between the ACL and an existing validated measure of psychopathy, the PCL-SV. Evidence for concurrent validity is thus indicated and in the direction predicted. The total ACL score was correlating with both Factor 1 and Factor 2 of the PCL-SV, further confirming validity, although the correlation was higher in relation to Factor 1 (interpersonal - personality) traits. This could suggest the ACL is more sensitive to the personality component of psychopathy which Factor 1 is argued to represent (Cooke \& Michie, 2001).

As predicted, Factor 1 scores of the PCL-SV correlated positively with the Affective, Cognitive and Interpersonal components of the ACL, with Affective the most highly associated, with correlations between the former two components moderate. There was a correlation between Affective and Cognitive and Factor 2 of the PCL-SV but this was low in relation to cognitive and moderate for affect. There was no correlation with the Interpersonal 
component of the ACL. Collectively these results suggest a more personality-focused element for Factor 1 of the PCL-SV which the ACL was aligning with in an expected fashion. Indeed, the prediction that the Lifestyle components of the ACL would correlate with Factor 2 of the PCL-SV was evidenced, with this producing a correlation of good magnitude, suggesting that the behavioural (Lifestyle) component of the ACL was clearly associating with the behavioural component of the PCL-SV. Overall, relationships between the component and factor scores indicate evidence both for concurrent and discriminate validity, the latter evidenced by the lack of correlations (or good correlations) between the ACL components and factor scores of the PCL-SV. For example, the absence of a correlation between the ACL interpersonal factor and the PCL-SV Factor 2 provides good evidence for discriminative validity since the interpersonal element should only associate with Factor 1.

Regarding implicit elements of the ACL, these were associating with psychopathy as measured by the PCL-SV. This indicated a role for implicit processing (e.g. Stacy \& Wiers, 2010) and thus for an associative processing system in psychopathy (Strack \& Deutsch, 2004). Consistent with the prediction made, implicit processing was associated with the total PCL-SV score and Factor 1 of the PCL-SV, but not for Factor 2. The prediction had indicated that implicit affect and cognitive elements would be positively associated with the personality component of psychopathy (i.e. Factor 1) as opposed to the behavioural component (i.e. Factor 2). The results supported this within a student sample. Although significant with a small sample, the correlations were not, however, of large magnitude but sufficient to suggest further exploration was warranted.

Consequently a need to explore in more detail the implicit processing system within the ACL was indicated. When implicit emotion was examined using its two subscales of 'correctly identified emotional words' and 'ability to feel emotions', the former was 
negatively correlated with the total ACL, total PCL-SV and total Factor 1 score. Thus, as psychopathy scores increased an individual's ability to correctly identify emotional words decreased. This was broadly consistent with research indicating that psychopathy was associated with difficulties in emotional recognition (Blair, 1995; Blair et al, 2005). A similar pattern was found across the subscale 'ability to feel emotions' where it was the personal experiencing of emotions (and not the ability to perspective-take regarding the emotions of others) that was associated with higher psychopathy scores on the ACL, PCL-SV and Factor 1. Not only do these results suggest convergence across the ACL and PCL-SV on the presentation of these specific elements of emotional processing, but the results also suggested that the correct placement of affect for student populations fell within the personality domain of psychopathic processing and not criminal history/lifestyle.

Regarding implicit cognition, poorer moral reasoning ability was equally associated with increased psychopathy scores on both the ACL and the PCL-SV, consistent with previous research noting difficulties in this area with psychopathy (Glenn et al, 2009; O'Kane, Fawcett \& Blackburn, 1996; Young et al, 2012). However, in the current study this ability difficulty was focused on the Factor 2 (antisocial behaviour) component of the PCLSV. It suggests that as a subsection of cognition (i.e. moral reasoning ability) may be better located within the behavioural domain of psychopathy. Interestingly, only the conventional moral judgement element was associated with increased psychopathy scores on the ACL. This could suggest that the ACL is more sensitive to assessing moral ability in comparison to the PCL-SV, or that the PCL-SV is simply more sensitive to the more behavioural manifestations of moral challenges. Indeed, the moral reasoning element of the ACL is perhaps a more implicit test of cognitive processing ability as it focuses on response generation and not the reporting of a more dichotomous conventional reasoning judgement more open to socially desirable responding. It was the moral reasoning aspect of cognition 
that appeared more important across measures, with no association found in relation to other aspects of cognition such as the conditional reasoning element (i.e. 'hostile responding'). There was, again, parity across the ACL and PCL-SV on this.

This parity also extended to the absence of an association between response times on the implicit tests on psychopathy. It could certainly be the case that the response time measure was simply not sensitive enough to response latency in a student sample, or that as a measure of implicit processing it was not associating with psychopathy.

The sample used in the current study was, however, relatively small and it was also restricted to men. It is, nevertheless, worth noting that for interview and ability assessment based research the sample size is within usual ranges. Problems with the sample are, however, acknowledged in that these represent a student population where estimates of psychopathy are not expected to be elevated. It becomes important therefore to further explore and attempt to replicate the findings noted here using a sample with higher expected levels of psychopathy. This proves the focus of the next two studies where there is an initial reliability study using a forensic sample, followed by one completed with high secure psychiatric patients where levels of psychopathy are argued to be most elevated.

\section{Participants}

\section{Study 3}

Eighty-four young adult male prisoners aged between 18 to 25 were approached. Eighty agreed to participate, representing a 95\% response rate. All were sampled from one establishment over a period of nine months. No demographic information concerning participants was collected to fulfil the requirement of ethical approval from the site which required total anonymity in reporting. 


\section{Overview}

The current study aimed to validate the ACL with an applied forensic sample, selected as those likely to present with behavioural and interpersonal difficulties. This selection was to determine if the ACL would apply to a group most likely to present with difficulties in the area of psychopathy as an initial validation before proceeding onto the final study. The current study also focused on the value to the ACL of incorporating collateral information within ratings.

Measure

The ACL was completed with this sample, as described for studies 1 and 2.

\section{Method}

As noted, the aim was to select prisoners who presented with behavioural and interpersonal challenges. Consequently, prisoners were randomly approached to take part if their name appeared on a prison database which included all those prisoners involved in, or suspected of being involved in, intra-group aggression (i.e. towards other prisoners) as either a perpetrator or a victim. Regarding the latter, prison research has long recognised that the 'victim' group more commonly represents a 'perpetrator-victim' group among prisoners, and those likely to present with the most significant behavioural and interpersonal challenges (Ireland, 2005; Ireland \& Ireland, 2008). For the purpose of this study, the database was considered for all entries in the 18 months prior to data collection. Of the 80 participants who consented to be interviewed, 47 were identified as perpetrators and 33 as victims.

All participants were interviewed on their own by a single interviewer (CM). This interviewer had been trained in the administration of the ACL and had conducted practice 
interviews prior to study commencement. The interviews took between 1 and 1.5 hours. Information to rate the collateral ratings for the ACL were gathered from prison reports.

Results

The overall ACL total produced an $\alpha$ of $.83(\mathrm{n}=80,33$ items). Coefficients were computed on all component scores. For ACL Affective this produced an $\alpha=.63(\mathrm{n}=80,7$ items). For ACL Cognitive, $\alpha=.48(\mathrm{n}=80,6$ items). ACL Lifestyle produced an $\alpha$ of .70 ( $\mathrm{n}$ $=80,11$ items) and ACL Interpersonal an $\alpha$ of $.57(\mathrm{n}=80,9$ items). Only one item negatively correlated across the scales, namely in relation to ACL Cognitive where the item 2B 'Cognitive Impulsivity’ increased the coefficient to .62.

The contribution of collateral information to reliability was also examined. To complete this items were scored incorporating the collateral information as opposed to considering the collateral as a distinct element. For each item where collateral was included the score on that item was re-coded to reflect the highest score. For example, if the affective item 'Callousness/lack of empathy' was rated a 2 on the interview (item 1B) and a 3 on the collateral (item 5A) then it was given an overall score of 3 . If the item was rated a 3 on the interview but 2 on the collateral then a score of 3 was retained.

Incorporating collateral information into the overall scale and component scales produced the following coefficients; ACL total, $\alpha$ of $.88(n=80,53$ items); ACL Affective an $\alpha=.76(\mathrm{n}=80,11$ items $) ;$ ACL Cognitive an $\alpha=.67(\mathrm{n}=80,11$ items $)$; ACL Lifestyle an $\alpha$ of $.77(n=80,21$ items); and ACL Interpersonal remaining with the same $\alpha$ of $.57(n=80,10$ items). No items negatively correlated. All future analyses therefore proceeded with the collateral information incorporated. Means across the total ACL and its component elements are indicated in Table 2. 
Correlations were computed between the component elements of the ACL; ACL Affective correlated positively with all components (Cognitive, $\mathrm{r}=.56, p=.001$; Lifestyle, $\mathrm{r}$ $=.62, p=.001 ;$ Interpersonal style, $\mathrm{r}=.33, p=.003)$; ACL Cognitive positively correlated with the remaining components (Lifestyle, $\mathrm{r}=.66, p=.001$; Interpersonal style, $\mathrm{r}=.43, p=$ $.001)$; Lifestyle and Interpersonal also positively correlated $(\mathrm{r}=.38, p=.001)$. All components of the ACL positively correlated with the total score (Cognitive, $\mathrm{r}=.82, p=$ $.001 ;$ Affective, $\mathrm{r}=.80, p=.001 ;$ Lifestyle, $\mathrm{r}=.90, p=.001 ;$ Interpersonal style, $\mathrm{r}=.59, p=$ $.001)$

\section{Discussion}

The results indicated that overall the ACL was internally reliable. The component scales ranged from moderately reliable (Affective, Cognitive, Interpersonal) to good (Lifestyle). However, the components comprised only a small number of items (between five and seven) which could explain their moderate reliability. Incorporating collateral information improved all reliabilities, raising them to at least good levels. The only exception to this was ACL Interpersonal which was not improved by the inclusion of collateral information. This could suggest that interpersonal components are not captured effectively by collateral information and thus nothing was added by collateral. The finding that collateral information generally improved all internal reliabilities did, nevertheless, suggest that with a forensic sample the measure is improved via the incorporation of such information.

Regarding limitations, it is accepted that the sample was specifically selected as likely to have the potential for increased risk of psychopathy and thus not truly random. However, the results provided an indication of sufficient internal reliability to examine the ACL in more detail in a further sample likely to present with increased levels of psychopathy. It also 
indicated a rationale for proceeding with an inclusion of collateral information with the final study.

Participants

\section{Study 4}

Forty adult male psychiatric patients from a high secure forensic psychiatric hospital took part. The average age was 40.1 years $(S D=9.0)$. Overall response rate was 37 per cent, with one patient removed from the dataset after completing only half the ACL.

Overview

Study four aimed to gather further information on the reliability of the ACL using a higher risk population and extending this to study the ACL's association with an existing measure of psychopathy to determine concurrent and discriminant validity. Predictions were the same as for study 2. The association between the implicit elements of the ACL and psychopathy were again examined.

Measure

The ACL and the PCL-SV were employed in the current study (see Study 2 for a description). Collateral as well as interview information was used to determine ratings on the ACL and on the PCL-SV.

\section{Method}

Responsible Clinicians provided consent for patients to be involved. Following this, patients were approached and invited to take part in the ACL and PCL-SV interview which lasted approximately 1.5 to 2 hours in total. During this time patients also provided consent for their records to be accessed. A small honorarium was paid to each participant. All interviews were conducted individually in a private room. The ACL was administered by 
three interviewers (ML, plus two research associates). All were trained in the use of the ACL and conducted practice interviews prior to formal administration. Scoring of the measures was completed separately so that the results of one measure (ACL) did not inform the results of the other (PCL-SV). Again, the authors of the ACL (CI and JI) did not participate in the scoring to maintain independence. Two patients declined to complete the implicit emotion tests. Their scores on the ACL were thus computed with these two items removed.

Results

Alpha coefficients were initially calculated across all measures and component scores using the interview data only. This produced the following results, ACL Total $\alpha=.86, \mathrm{n}=$ 38, 33 items; ACL Affective $\alpha=.71(\mathrm{n}=38,7$ items); ACL Cognitive, $\alpha=.48(\mathrm{n}=40,6$ items); ACL Lifestyle $\alpha$ of .77 ( $\mathrm{n}=40,11$ items); ACL Interpersonal, $\alpha$ of .74 $(\mathrm{n}=40,9$ items); PCL-Total, $\alpha$ of $.69(n=40,12$ items); PCL-SV Factor 1, $\alpha$ of $.63(n=40,6$ items) and PCL-SV Factor 2, $\alpha$ of .64 $(\mathrm{n}=40,6$ items). No items negatively correlated across any of the scales aside from; 4C Interpersonal Controlling; 4E Interpersonal Manipulative and 4I Interpersonal Impulsivity. All these items negatively correlated with the overall ACL scale but did not impact overall on reliability.

Alpha coefficients were then calculated on the ACL incorporating the collateral scores as for study 3, with the following results; Total ACL $\alpha=.89, \mathrm{n}=38,33$ items; ACL Affective $\alpha=.68, \mathrm{n}=38,7$ items; ACL Cognitive, $\alpha=.66, \mathrm{n}=40,6$ items; ACL Lifestyle $\alpha$ of .76, $\mathrm{n}=40,11$ items; and ACL Interpersonal, $\alpha$ of .72, $\mathrm{n}=40,9$ items. No items negatively correlated across any of the scales aside from; 4C Interpersonal Controlling and 4E Interpersonal Manipulative, which negatively correlated with the overall ACL scale but did not impact overall on reliability. Means across the total ACL and PCL-SV and their respective component elements are indicated in Table 2. 


\section{$\underline{\text { Association between ACL and PCL-SV }}$}

Correlations were computed between the ACL and PCL-SV. Using ACL scores based on the interview data only produced the following results: Total ACL scores and total PCL-SV $r=.72, p=.001$; ACL total scores and Factor 1 and 2 of the PCL-SV, $r=.50, p=$ .001 and $r=.64, p .001$ respectively; PCL-SV total and the ACL components of Cognitive ( $r$ $=.58 p=.001)$, Affective $(r=.52, p=.001)$, Interpersonal $(r=.29, p=.06)$ and Lifestyle $(r=$ $.69, p=.001)$. Across PCL-SV factor components, Factor 1 correlated positively with the following ACL components (Cognitive, $r=.53 p=.001$; Interpersonal, $r=.34, p=.03$; Lifestyle, $r=.46, p=.003)$ but not ACL Affective ( $r=.18 \mathrm{~ns})$. Factor 2 correlated positively with ACL Cognitive $(r=.39, p=.01)$, ACL Affective $(r=.65, p=.001)$ and ACL Lifestyle $(r$ $=.63, p=.001)$ but not with ACL Interpersonal $(r=.13 \mathrm{~ns})$.

Correlations were repeated using the ACL scores that incorporated collateral information. This improved all associations, producing the following results: Total ACL scores and total PCL-SV $r=.84, p=.001$; ACL total scores and Factor 1 and 2 of the PCL$\mathrm{SV}, r=.65, p=.001$ and $r=.69, p=.001$ respectively; PCL-SV total and the ACL components of Cognitive $(r=.76, p=.001)$, Affective $(r=.60, p=.001)$, Interpersonal $(r=$ $.32, p=.02)$ and Lifestyle $(r=.82, p=.001)$. Across PCL-SV factor components, Factor 1 correlated positively with all ACL components (Cognitive, $r=.71, p=.001$; Interpersonal, $r=$ $.41, p=.008$; Lifestyle $r=.56, p=.001$; Affective, $r=.33, p=.04)$. Factor 2 correlated positively with ACL Cognitive $r=.49, p=.001$, ACL Affective $r=.63, p=.001$, and ACL Lifestyle $(r=.74, p=.001)$ but not with ACL Interpersonal $(r=.17 \mathrm{~ns})$.

Association between ACL implicit functioning and psychopathy

The four implicit sets of tests within the ACL were examined in more detail as for Study 3 (see Table 3). These were compared to the overall ACL total as well as the PCL-SV 
scores, with the PCL-SV and ACL both incorporating collateral information. Increased response time to identifying emotional words increased as psychopathy scores increased on the PCL-SV $(\mathrm{r}=.37, p=.02)$ but decreased as PCL-SV Factor 1 scores increased $(-.47, p=$ .001). No correlations were noted between the ability to rank emotions and either the PCLSV or the ACL, with one small correlation with response time and total ACL. Specifically, as the time to complete the ranking emotions test increased, the total ACL score decreased.

Implicit cognition with regards to moral reasoning was, however, correlating with psychopathy scores with the total number of reasons provided for the judgement decreasing as the scores on psychopathy increased. This held for total PCL-SV $(r=-.44, p .001)$, Factor 1 PCL-SV $(r=-.39, p .001)$, Factor 2 PCL-SV $(r=-.30, p=.05)$ and total ACL $(r=-.46, p$. 001). Response time in relation to moral reasoning was also associating with psychopathy scores, with decreased time to complete the moral reasoning tests associated with higher levels of Factor 2 PCL-SV and total ACL scores $(\mathrm{r}=-.34, p=.02$ and $\mathrm{r}=-.37, p=.02$ respectively). There were no further significant correlations.

\section{Discussion}

The ACL was again indicated to be reliable, with the addition of collateral information assisting further with this overall, particularly regarding the cognitive components. It did not impact on the interpersonal component although this incorporated only collateral items, which explains a lack of change. As predicted, the ACL positively correlated with an existing measure of psychopathy with this association enhanced if collateral information was incorporated. This provided further evidence of validity with the ACL, with the finding of an association across both factors of the PCL-SV suggesting that in a forensic sample it was correlating equally across the interpersonal-personality (Factor 1) and behavioural (Factor 2) components of psychopathy. 
Regarding the prediction that the affective, cognitive and interpersonal components of the ACL would positively correlate with the interpersonal (Factor 1) component of the PCL$\mathrm{SV}$, this held only for cognition and interpersonal, not for affect when using interview data only. However, when collateral information was incorporated all ACL elements were associated including affect, albeit the weakest association. It suggests that within the current sample the affect elements were not associating as predicted and as expected by the literature (e.g. Blair et al, 2005; Dawel et al, 2012; Hastings et al, 2008). As predicted, the Lifestyle component of the ACL was positively associated with the Factor 2 (criminal history and lifestyle) component of the PCL-SV. This again was improved on when collateral information was incorporated into the ACL. The ACL Lifestyle component correlated more strongly with Factor 2 than Factor 1.

Finally, the prediction that the implicit elements of the ACL (affect and cognition) would be positively associated with the personality component of psychopathy (Factor 1 PCL-SV) and not the behavioural component (i.e. Factor 2 PCL-SV) was not wholly supported. Implicit affect did not correlate, aside from the response time for emotional word identification; as response time increased the overall PCL-SV score increased and decreased for Factor 1 scores. This suggests that in a forensic sample the identification of emotional words was failing to associate with psychopathy but response latency was a factor. This appeared further supported by the correlation (albeit small) between response time and the ability to rank emotions, with response time decreasing as the ACL total increased.

Implicit cognition did associate with psychopathy levels, as predicted, but only in relation to moral reasoning and not in relation to conditional [hostile] responding. Moral reasoning was also associating across all measurements of psychopathy, with decreased reasoning ability associated with increased levels of total psychopathy (ACL and PCL-SV) and for both Factor 1 and Factor 2. This again supported evidence for moral reasoning as a 
core component of psychopathy (Glenn et al, 2009; O'Kane, Fawcett \& Blackburn, 1996; Young et al, 2012) but not conventional moral reasoning (Stevens et al, 2012).

The findings regarding implicit affect and cognition differed therefore from those indicated in study 2 involving students. It could certainly be the case that the current findings were informed by the use of collateral information. Equally it could suggest that the samples and how psychopathy associates with variables are distinct. There was, however, commonality regarding moral reasoning which suggests a consistent element across samples. Implicit emotion, however, certainly appears to be associating differently for the forensic sample with response latency appearing as a factor of interest both for this and also for the implicit cognition element of moral reasoning. It appears that forensic patients with higher levels of psychopathy are slower at completing some elements of implicit affect and cognition assessments. Hostile responding continues to present as a factor that is not associating with psychopathy which is inconsistent with the literature (Vitale et al., 2005) but in keeping with the findings for study 2. This suggests that implicit conditional (hostile) responding as examined by the ACL is not a feature of psychopathy in either a student or a forensic sample.

There are, nevertheless, limitations associated with the current study that need to be acknowledged. There was more than one interviewer utilised which could have impacted, although all were trained in administration and completed practice interviews. The sample size is limited and specialised suggesting generalising may be challenged. The unique nature of the sample could equally be considered advantageous regarding application but, nevertheless, requires acknowledgement. The current study does indicate an association between the ACL and PCL-SV suggesting convergence, with implicit measures of functioning also proving of interest although in a localised manner. 
General discussion

Interest in developing assessments for psychopathy has been evidenced for over two decades (e.g. Cooke et al, 2004; Hare, 1991, 1997; Kosson et al, 1997; Levenson et al, 1995; Lilienfeld \& Andrews, 1996; Lynam et al, 2011; Patrick, 2010). Focus has been on the development of explicit measures with few (e.g. Hare, 1991; Hare, 1997; Cooke et al, 2004) combining sources of information to form a judgement. The ACL presents some initial results suggesting value in an approach that utilises a range of information sources, extended to incorporate implicit as well as explicit content.

The current series of studies demonstrates evidence for the internal reliability of the ACL and its validity with another measure of psychopathy across both a student and forensic sample. The studies also suggest the reliability and validity of the ACL can be enhanced with forensic samples by incorporating collateral information. Some consistency between samples regarding the specific nature of the associations between the ACL and PCL-R components was evidenced. For example, the interpersonal component of the ACL did not correlate with Factor 2 of the PCL-SV (if incorporating collateral information for the forensic sample), which was consistent with the prediction made based on the argument that the interpersonal elements of psychopathy represent the personality component (Cooke \& Michie, 1997, 2001). Thus it should not be expected to associate with the behavioural component of psychopathy (i.e. Factor 2, PCL-SV). Equally, the ACL lifestyle components correlated highest with Factor 2 PCL-SV. This was expected since both focused on the behavioural elements of psychopathy but were, nevertheless, scored independently.

There was also evidence of discrimination between samples, with those considered at higher risk for psychopathy (i.e. prisoners and forensic psychiatric; Hare, 2003) presenting with higher levels of psychopathy on the ACL than the lower risk student samples (see Table 2; footnote a). The ACL therefore appears able to discriminate effectively across samples, 
with this controlling for the absence of collateral information available for the student samples. In addition, the forensic [adult] psychiatric sample were presenting with the highest total ACL scores than the [young] prisoner sample. The former would represent a higher risk sample for psychopathy (Hare, 2003) of these two forensic groups, suggesting the ACL is also able to discriminate between forensic samples.

The ACL does indicate value in incorporating specific elements of implicit cognition as important to psychopathy, namely moral reasoning ability. Cognition has been neglected from measures of psychopathy (Blackburn, 2003, 2007) with the current studies highlighting the importance of cognition and supporting previous research which argued for its incorporation (e.g. Blair et al, 2005; Wallace et al, 2000). However, the current study argues for its importance in a localised manner; hostile responding, for example, was not a component of implicit cognition (Blackburn, 2003; Vitale et al, 2005). This was a surprising finding that held across forensic and student samples. It could be the case that the specific measure of implicit cognition was not sufficiently sensitive but, regardless, it suggests that for an ACL assessment of psychopathy it should not contribute to the psychopathy score. Similarly, the use of response latency within the implicit assessments as a contributing element to determining levels of psychopathy appears likely unhelpful considering its value only with the forensic sample. Again, however, the response time variable may not have been sufficiently sensitive to differences and thus the results could be a result of this.

The findings in relation to moral reasoning were of particular interest. Moral abilities are thought associated with psychopathy (e.g. Blair, 1995; Blair et al, 1995; Glenn et al, 2009; O'Kane et al, 1996; Young et al, 2012) with the current study suggesting that it is not associated globally but specifically; it was not the more traditional element of moral judgement (i.e. conventional reasoning) that appeared to relate (e.g. Stevens et al, 2012) but the specific element relating to reasoning ability. It is certainly possible that the conventional 
reasoning element is more open to socially desirable responding due to potential transparency, whereas the reasoning element (i.e. ability to generating reasons for the decision) is less likely to be effected in this manner. It could therefore represent the more implicit of the two measures (i.e. conventional judgement versus moral reasoning). This finding is also in keeping with research supporting the application of information processing theories to understanding psychopathy where the reasoning element underlying cognition may represent the dominating feature (e.g. Wallace et al, 2000). It would certainly be consistent with the more associative system of processing (Strack \& Deutsch, 2004).

Overall the findings support a role for implicit processing in psychopathy, with consistency in implicit cognitive functioning across samples. Affect is also noted as an important element of psychopathy (e.g. Cleckley, 1976; Cooke \& Michie, 2001; Hastings et al, 2008; Dawel et al, 2012) although it may not have uniform application across samples. There was certainly evidence for a differential relationship in affect between forensic and student samples, with the ability to identify emotions and to rank their impacts presenting as more important among non-forensic groups. Implicit affect did not associate with the forensic sample beyond response latency. Findings therefore suggest uniformity in the relationship between implicit cognition and psychopathy across samples, but an unclear relationship between implicit affect and psychopathy in a forensic sample. It does justify inclusion for implicit elements to be incorporated in psychopathy assessments, however, certainly in relation to cognition which has perhaps represented the most neglected of the psychopathy assessment elements (e.g. Blackburn, 2003, 2007).

Indeed, the differential results across the samples are worthy of mention. There is a tendency for research to comment on psychopathy as a uniform concept across samples, failing to account for how the traits of psychopathy may manifest differently across samples. How, for example, does a community psychopath behave in comparison to an offender 
psychopath? It has been argued that Factor 2 type traits (criminal history and lifestyle) are clearly a differential factor between such groups (Blackburn, 2007; Cooke \& Michie, 2001) but what continues to be missing from the literature are the Factor 2 equivalent traits in a non-forensic sample. Adhering more closely to the Cleckley $(1976,1982)$ definition as opposed to that offered by the PCL (Hare, 2003) is arguably one initial means of avoiding an over focus on criminality. This was one of the core aims of the ACL; namely to operationalise a description of psychopathy which did not centre on antisocial behaviour and criminality but adopted a broader outline of what this concept could include (see Table 1). It was aiming to be sensitive to levels of psychopathy across differing samples.

Considering differences across samples, with the student sample the ACL total was correlating highest with Factor 1 of the PCL-SV. This would suggest it was more sensitive therefore to the personality component of psychopathy (Cooke \& Michie, 2001). In the forensic (psychiatric) sample, however, the positive correlations between ACL total and PCL-SV Factor 1 and Factor 2 were broadly equivalent, suggesting it was associating with both the personality and behavioural components equally. This could represent a product of higher levels of Factor 2 traits in the forensic sample, but equally could suggest that psychopathy is not presenting similarly across samples. It is certainly possible to suggest that psychopathy within non-forensic samples may be more personality than behaviourally related, in that the behavioural manifestations of psychopathy are not so clearly evidenced. Equally, sample age could impact in that behavioural manifestations in the younger (student) sample are not evidenced as much as in an older (forensic sample). Regardless of this, the ACL was not relating differently across PCL-SV factors in the latter sample.

There are undoubtedly limitations associated with the current study that need to be acknowledged. The ACL is a newly developed measure that did not employ expert consultation to aid its development, relying instead on a review of the literature. This 
approach was adopted since expert reviews are known to simply reproduce the PCL criteria (Kreis et al, 2012) when the current aim was to develop an approach informed by the literature on psychopathy and not restricted to a review of existing measures of psychopathy. Nevertheless, the ACL would benefit from further research focusing on the validity of its components and also its potential for detecting change across time. The sample size was also moderate within each sample, but acceptable for a method involving a range of assessments being applied (i.e. interview, collateral, observation, completion of implicit tests and genogram style assessments). The sampling would, nevertheless, benefit from a larger participant size and expansion across sex and population type. Engagement of participants across samples was also generally good although the most specialised sample (high secure forensic psychiatric: study 4) was the hardest to engage, resulting in the lowest response rates. Finally, there are issues relating to bias within the data collection procedures, with this controlled by using different interviewers across each study. The ACL psychopathy scoring was also completed post interview and separately from the PCL-SV scoring. Furthermore the ACL is structured so that it is not possible to determine levels of psychopathy until all the final scores are considered. These were all completed post data collection. The authors of the ACL (Ireland, J; Ireland, C) also maintained independence from the scoring of the individual ACL items used to calculate an overall level of psychopathy.

Overall the results indicate evidence for the internal reliability of the ACL with some initial promising evidence for validity. The value of incorporating explicit and implicit assessment is also indicated. Including implicit and explicit processing further allows some control over false reporting (Bluemke et al, 2009; Snowden et al, 2004), with collateral information also appearing as an important inclusion for forensic populations.

The ACL thus has potential as a developing measure for the assessment of psychopathy which is closely aligned to the literature and original formulations of 
psychopathy. It also captures cognition and affect equally, appearing sensitive to differences in populations, and correlates well with an existing clinical measure of psychopathy. It does, however, represent an assessment approach which requires more research utilising a range of samples and increased sample sizes. Future research could also widen the incorporation of cognition, examine emotional recognition using further implicit means, and incorporate adaptive (i.e. positive) qualities into the ACL to make it a more holistic assessment. Nevertheless, it appears a promising approach and the only one currently available that attempts to capture implicit processing.

\section{References}

Back, M. D., Schmukle, S. C., Egloff, B. (2009). Predicting actual behavior from the explicit and implicit self-concept of personality. Journal of Personality and Social Psychology, 97, 533-548.

Baskin-Sommers, A. R., Curtin, J. J., Newman, J. P. (2013). Emotion-modulated startle in psychopathy: Clarifying familiar effects. Journal of Abnormal Psychology, 122, 458468.

Blackburn, R. (2003). Psychopathy and the contribution of personality to violence. In T. Millon, E. Simonsen, M. Birket-Smith, \& R. D. Davis (Eds.), Psychopathy: Antisocial, criminal, and violent behavior(pp. 50-68). New York: The Guildford Press.

Blackburn, R. (2007). Personality disorder and antisocial deviance: Comments on the debate on the structure of the Psychopathy Checklist-Revised. Journal of Personality Disorders, 21, 142-159.

Blair, R. J. R. (1995). A cognitive developmental approach to morality: Investigating the psychopath. Cognition, 57, 1-29. 
Blair, R. J. R., Mitchell, D. G. V., Peschardt, K. S., Colledge, E., Leonard, R. A., Shine, J. H., Murray, L. K., Perrett, D. I. (2004). Reduced sensitivity to others' fearful expressions in psychopathic individuals. Personality and Individual Differences, 37, 1111-1122.

Blair, J., Mitchell, D., \& Blair, K. (2005). The psychopath: Emotion and the brain. Oxford: Blackwell Publishing.

Bluemke, M., Friedrich, M., Zumbach, J. (2010). The influence of violent and non-violent computer games on implicit measures of aggressiveness. Aggressive Behavior, 36, 113.

Butler, J (2008). The family diagram and genogram: Comparisons and contrasts. American Journal of Family Therapy, 12, 36 (3): 169-180. doi:10.1080/01926180701291055

Cleckley, H. (1976). The mask of sanity ( $5^{\text {th }}$ ed.). St. Louis, Missouri: The C. V. Mosby Company.

Cleckley, H. (1982). The mask of sanity (rev ed.). St. Louis, Missouri: The C. V. Mosby Company.

Cooke, D. J., Michie, C. (1997). An item response theory analysis of the Hare psychopathy checklist - revised. Psychological Assessment, 9, 3-14.

Cooke, D. J., Michie, C. (2001). Refining the construct of psychopathy: Towards a hierarchical model. Psychological Assessment, 13, 171-188.

Cooke, D. J., Hart, S. D., Logan, C., Michie, C. (2004). Comprehensive Assessment of Psychopathic Personality - Institutional Rating Scale (CAPP-IRS). Unpublished Manual.

Cramer, P. (1968). Word Association. Academic, Saint Louis, MO.

Dawel, A., O’Kearney, R., McKone, E., Palermo, R. (2012). Not just fear and sadness: Metaanalytic evidence of pervasive emotion recognition deficits for facial and vocal 
expressions in psychopathy. Neuroscience and Biobehavioral Reviews, 36, 22882304.

De Houwer, J, Teige-Mocigemba, S, Spruyt, A., Moors, A. (2009). Implicit measures: A normative analysis and review. Psychological Bulletin, 135, $347-68$.

Glass, S. J., Newman, J. P. (2009). Emotion processing in the criminal psychopath: The role of attention in emotion-facilitated memory. Journal of Abnormal Psychology, 118, 229-234.

Glenn, A. L., Iyer, R., Graham, J., Koleva, S., Haidt, J. (2009). Are all types of morality compromised in psychopathy? Journal of Personality Disorders, 23, 384-398.

Greenwald, A. G., McGhee, D. E., Schwartz, J. L. K. (1998). Measuring individual differences in implicit cognition: The Implicit Association Test. Journal of Personality and Social Psychology, 74, 1464-1480.

Hare, R. D. (1985). A comparison of procedures for the assessment of psychopathy. Journal of Consulting and Clinical Psychology, 53, 7-16.

Hare, R. D. (1991). The Hare Psychopathy Checklist-Revised. Toronto, Ontario: Multi-Health Systems.

Hare, R. D. (2003). The Hare Psychopathy Checklist-Revised, $2^{\text {nd }}$ edition. Toronto, Ontario: Multi-Health Systems.

Hart, S., Cox, D., Hare, R. D. (1995). Manual for the Psychopathy Checklist: Screening Version (PCL:SV). Toronto: Multi-Health Systems.

Hastings, M. E., Tangney, J. P., Stuewig, J. (2008). Psychopathy and identification of facial expressions of emotion. Personality and Individual Differences, 44, 1474-1483.

Hofmann, W., Friese, M. (2008). Impulses got the better of me: Alcohol moderates the influence of implicit attitudes towards food cues on eating behaviour. Journal of Abnormal Behavior, 117, 420 - 427. 
Ireland, J. L. (2005). Bullying among prisoners: The need for innovation. In J. L Ireland (Ed.), Bullying among prisoners: Innovations in theory and research (pp. 1-30), Hove: Willan Publishing.

Ireland, J. L., Ireland, C. L. (2008). Intra-group aggression among prisoners: Frequency of bullying and exploration of victim-perpetrator mutuality. Aggressive Behavior, 34, 76-87.

Ireland, J. L., Adams, C. (in press). Implicit aggression among young male prisoners: Association with dispositional and current aggression. International Journal of Psychiatry and Law.

Ireland, J. L., Birch, P. (2013). Emotionally abusive behavior in young couples: Exploring a role for implicit aggression. Violence and Victims, 28, 656-669.

Ireland, J. L., Ireland, C. A. (2012). Affective, Cognitive, and Lifestyle Assessment (ACL). The University of Central Lancashire, UK and TIOFP, UK.

Iria, C., Barbosa, F., Paixão, R. (2012). The identification of negative emotions through a go/no-go task: Comparative research in criminal and non-criminal psychopaths. European Psychologist, 17, 291-299.

Johansson, P., Andershed, H., Kerr, M., Lavander, S. (2002). On the operationalization of psychopathy: Further support for a three-faceted personality orientated model. ActaPsychiatricaScandanvica,106, 81-85.

Kosson, D. S., Stuerwald, B. L., Forth, A. E., Kirkhart, K. J. (1997). A new method for assessing the interpersonal behaviour of psychopaths: Preliminary validation studies. Psychological Assessment, 9, 89-101.

Kreis, M. K. F., Cooke, D. J., Michie, C., Hoff, H. A., Logan, C. (2012). The Comprehensive Assessment of Psychopathic Personality (CAPP): Current validation using prototypical analysis. Journal of Personality Disorders, 26, 402-413. 
Levenson, M. R., Kiehl, K. A., Fitzpatrick, C. M. (1995). Assessing psychopathic attributes in a non-institutionalized population. Journal of Personality and Social Psychology, 68, 151-158.

Lilienfeld, S. O., Andrews, B. P. (1996). Development and preliminary validation of a selfreport measure of psychopathic personality traits in noncriminal populations. Journal of Personality Assessment, 66, 488-524.

Loham, D. F., Hagen, E. P (2001). CogAT: Cognitive Abilities Test. Riverside Publishing: Houghton, Mifflin, Harcourt, US.

Loranger, A. Janca., N. Sartorius (2007). Assessment and Diagnosis of Personality Disorders. International Personality Disorder Examination (IPDE). Cambridge University Press.

Lorenz, A. R., Newman, J. P. (2002). Deficient response modulation and emotion processing in low-anxious Caucasian psychopathic offenders: Results from a lexical decision task. Emotion, 2, 91-104.

Lykken, D. T. (1957). A study of anxiety in the sociopathic personality. Journal of Abnormal and Social Psychology, 55, 6-10.

Lynam, D. R., Gaughan, E. T., Miller, J. D., Miller, D. J., Mullins-Sweatt, S., Widiger, T. A. (2011). Assessing the basic traits associated with psychopathy: Developmental and validation of the elemental psychopathy assessment. Psychological Assessment, 23, 108-124.

Montagne, B., Van Honk, J., Kessels, R. P. C., Frigerio, E., Burt, M., Van Zandvoort, M. J. E., Perrett, D. I., De Haan, E. H. F. (2005). Reduced efficiency in recognising fear in subjects scoring high on psychopathic personality characteristics. Personality and Individual Differences, 38, 5-11. 
Neumann, C. S., Hare, R. D., Johansson, P. T. (2013). The Psychopathy Checklist-Revised (PCL-R), low anxiety, and fearlessness: A structural equation modelling analysis. Personality Disorders: Theory, Research, and Treatment, 4, 129-137.

Neumann, C. S., Kosson, D. S., Forth, A. E., Hare, R. D. (2006). Factor structure of the Hare Psychopathy Checklist: Youth Version (PCL:YV) in incarcerated adolescents. Psychological Assessment, 2, 142-154.

Newman, J. P., MacCoon, D. G., Vaughn, L. J., Sadeh, N. (2005). Validating a distinction between primary and secondary psychopathy with measures of Gray's BIS and BAS constructs. Journal of Abnormal Psychology, 114, 319-323.

Newman, J. P., Schmitt, W. A., Voss, W. D. (1997). The impact of motivationally neutral cues on psychopathic individuals: Assessing the generality of the Response Modulation Hypothesis. Journal of Abnormal Psychology, 106, 563-575.

O'Kane, A., Fawcett, D., Blackburn, R. (1996). Psychopathy and moral reasoning: Comparison of the two classifications. Personality and Individual Differences, 20, $505-514$.

Patrick, C. J. (2010). Triarchic Psychopathy Measure (TriPM).

Reise, S. P., Oliver, C. J. (1994). Development of a California Q-set indicator of primary psychopathy. Journal of Personality Assessment, 62, 130-144.

Segal, Z. V. (1988). Appraisal of the self-schema construct in cognitive models of depression. Psychological Bulletin, 103, 147-162.

Sevecke, K., Pukrop, R., Kosson, D. S., Krischer, M. K. (2009). Factor structure of the Hare Psychopathy Checklist: Youth Version in German female and male detainees and community adolescents. Psychological Assessment, 21, 45-56. 
Skeem, J. L., Cooke, D. J. (2010). Is criminal behavior a central component of psychopathy? Conceptual directions for resolving the debate. Psychological Assessment, 22, 433445.

Snowden, R. J., Gray, N., Smith, J., Morris, M., MacCulloch, M. J. (2004). Implicit affective associations to violence in psychopathic murders. The Journal of Forensic Psychiatry and Psychology, 15, 620-641.

Stacy, A. W., Wiers, R. W. (2010). Implicit cognition and addiction: A tool for explaining paradoxical behaviour. Annual Review of Clinical Psychology, 6, 551-575.

Stevens, G. W., Deuling, J. K., Armenakis, A. A. (2012). Successful psychopaths: Are they unethical decision-makers and why? Journal of Business Ethics, 105, 139-149.

Stewart, SH, Hall, E, Wilkie, H, Birch, CD (2002). Affective priming of alcohol schema in coping and enhancement motivated drinkers. Cognitive Behavioural Therapy, 31: $68-80$.

Strack, F., Deutsch, R. (2004). Reflective and impulsive determinants of social behaviour. Personality and Social Psychology Review, 8, 220-247.

Vitacco, M. J., Neumann, C. S., Jackson, R. L. (2005). Testing a four-factor model of psychopathy and its association with ethnicity, gender, intelligence, and violence. Journal of Consulting and Clinical Psychology, 73, 466-476.

Vitale, J. E., Newman, J. P., Serin, R. C., Bolt, D. M. (2005). Hostile attributions in incarcerated adult male offenders: An exploration of diverse pathways. Aggressive Behavior, 31, 99-115.

Wallace, J. F., Schmitt, W. A., Vitale, J. E., Newman, J. P. (2000). Experimental investigations of information-processing deficiencies in psychopaths: Implications for diagnosis and treatment. In C. B. Gacono (Ed.), The clinical and forensic assessment of psychopathy (pp. 87-110). London: Lawrence Erlbaum. 
Weschler, D. (2008). Weschler Adult Intelligence Scale ( $4^{\text {th }}$ Ed.), San Antonio TX: Psychological Corporation and Pearsons UK.

Wilson, B. A., Alderman, N., Burgess, P. W, Emslie, H. E., Evans, J. J. (1996). Behavioural Assessment of the Dysexecutive Syndrome. Bury St Edmunds, UK: Thames Valley Test Company.

Young, L., Koenigs, M., Kruepke, M., Newman, J. P. (2012). Psychopathy increases perceived moral permissibility of accidents. Journal of Abnormal Psychology, 121, 659-667.

Zeelenberg, R,Shiffrin, RM, Raaijmakers, JGW. (1999). Priming in a free association task as a function of association directionality, Memory \& Cognition, $27: 956-961$ 
Table 1. Content of the ACL

\begin{tabular}{|c|c|c|c|c|c|}
\hline ACL area & Theme identified from literature & $\begin{array}{l}\text { Implicit, } \\
\text { explicit or } \\
\text { observation }\end{array}$ & How assessed & $\begin{array}{l}\text { Collateral } \\
\text { item? }\end{array}$ & $\begin{array}{l}\text { ACL composite } \\
\text { item (no of } \\
\text { items) }\end{array}$ \\
\hline Affective & Difficulty in recognising emotions & Explicit & Interview & $\mathrm{N}$ & $1 \mathrm{~A}(3)$ \\
\hline Affective & Callousness/lack of empathy & Explicit & Interview & $\mathrm{Y}$ & 1B (4) \\
\hline Affective & Emotional impulsivity & Explicit & Interview & $\mathrm{Y}$ & $\mathrm{IC}(1)$ \\
\hline Affective & Anger/irritability & Explicit & Interview & Y & $1 \mathrm{D}(3)$ \\
\hline Affective & Problems in identifying emotions & Implicit & Puzzle plus response time & $\mathrm{N}$ & $1 \mathrm{E}$ \\
\hline Affective & Problems in feeling emotions & Implicit & Event stories plus response time & $\mathrm{N}$ & $1 \mathrm{~F}$ \\
\hline Affective & Lack of guilt/remorse \& willingness to exploit & Explicit & Interview & Y & $2 \mathrm{~A}(3)$ \\
\hline Cognitive & Cognitive impulsivity & Explicit & Interview & $\mathrm{Y}$ & 2B (1 item) \\
\hline Cognitive & Difficulties with moral judgements/ reasoning & Implicit & $\begin{array}{l}\text { Moral scenarios plus response } \\
\text { time and number of reasons }\end{array}$ & $\mathrm{N}$ & $2 \mathrm{C}$ \\
\hline Cognitive & Hostile responding & Implicit & Conditional reasoning scenarios & $\mathrm{Y}$ & $2 \mathrm{D}$ \\
\hline Lifestyle & Poor quantity of interpersonal relationships & Explicit & Interview & $\mathrm{Y}$ & $3 \mathrm{~A}$ \\
\hline Lifestyle & General poor quality of interpersonal relationships & Explicit & Genogram patterns & Y & 3B \\
\hline Lifestyle & $\begin{array}{l}\text { Poor quality of interpersonal relationships, } \\
\text { characterised by aggression }\end{array}$ & Explicit & Genogram patterns & $\mathrm{Y}$ & $3 \mathrm{C}$ \\
\hline Lifestyle & Tendency towards being aggressive & Explicit & Interview & $\mathrm{Y}$ & 3D (2 items) \\
\hline Cognitive & Uncaring/callous view towards aggression use & Explicit & Interview & Y & $3 \mathrm{E}(2$ items \\
\hline
\end{tabular}




\begin{tabular}{|c|c|c|c|c|c|}
\hline ACL area & Theme identified from literature & $\begin{array}{l}\text { Implicit, } \\
\text { explicit or } \\
\text { observation }\end{array}$ & How assessed & $\begin{array}{l}\text { Collateral } \\
\text { item? }\end{array}$ & $\begin{array}{l}\text { ACL composite } \\
\text { item (no of } \\
\text { items) }\end{array}$ \\
\hline Lifestyle & Tendency to be cruel or humiliate others & Explicit & Interview & $\mathrm{Y}$ & $3 \mathrm{~F}(2$ items $)$ \\
\hline Cognitive & $\begin{array}{l}\text { Uncaring/callous view towards use of } \\
\text { cruelty/humiliation }\end{array}$ & Explicit & Interview & Y & $3 \mathrm{G}$ (2 items) \\
\hline Lifestyle & Tendency to manipulate & Explicit & Interview & Y & $3 \mathrm{H}$ (2 items) \\
\hline Cognitive & Tendency towards narcissism & Explicit & Interview & Y & 3I (2 items) \\
\hline Lifestyle & Irresponsibility/poor planning & Explicit & Interview & Y & $3 \mathrm{~J}(6$ items $)$ \\
\hline Lifestyle & Thrill and adventure seeking & Explicit & Self-report scale & $\mathrm{Y}$ & $3 \mathrm{~K}(6$ items $)$ \\
\hline Lifestyle & Susceptibility to boredom & Explicit & Self-report scale & $\mathrm{Y}$ & $3 \mathrm{~N}(6$ items $)$ \\
\hline Lifestyle & Criminal tendency & Explicit & Interview & $\mathrm{Y}$ & $3 \mathrm{P}$ (2 items) \\
\hline Lifestyle & Inability to learn from punishment & Explicit & Interview & $\mathrm{N}$ & 3Q (1 item) \\
\hline Interpersonal & Paucity of emotional content & Implicit & Observational & - & $4 \mathrm{~A}$ \\
\hline Interpersonal & Superficial content/style & Implicit & Observational & - & $4 \mathrm{~B}$ \\
\hline Interpersonal & Controlling style & Implicit & Observational & - & $4 \mathrm{C}$ \\
\hline Interpersonal & Aggressive/hostile style & Implicit & Observational & - & $4 \mathrm{D}$ \\
\hline Interpersonal & Manipulative style & Implicit & Observational & - & $4 \mathrm{E}$ \\
\hline Interpersonal & Less than honest style & Implicit & Observational and collateral & $\mathrm{Y}$ & $4 \mathrm{~F}$ \\
\hline Interpersonal & Self-important style & Implicit & Observational & - & $4 \mathrm{G}$ \\
\hline Interpersonal & Susceptibility to boredom & Implicit & Observational & - & $4 \mathrm{H}$ \\
\hline Interpersonal & Impulsive style & Implicit & Observational & - & $4 \mathrm{I}$ \\
\hline
\end{tabular}


Table 2

Mean scores on ACL and PCL-SV across samples

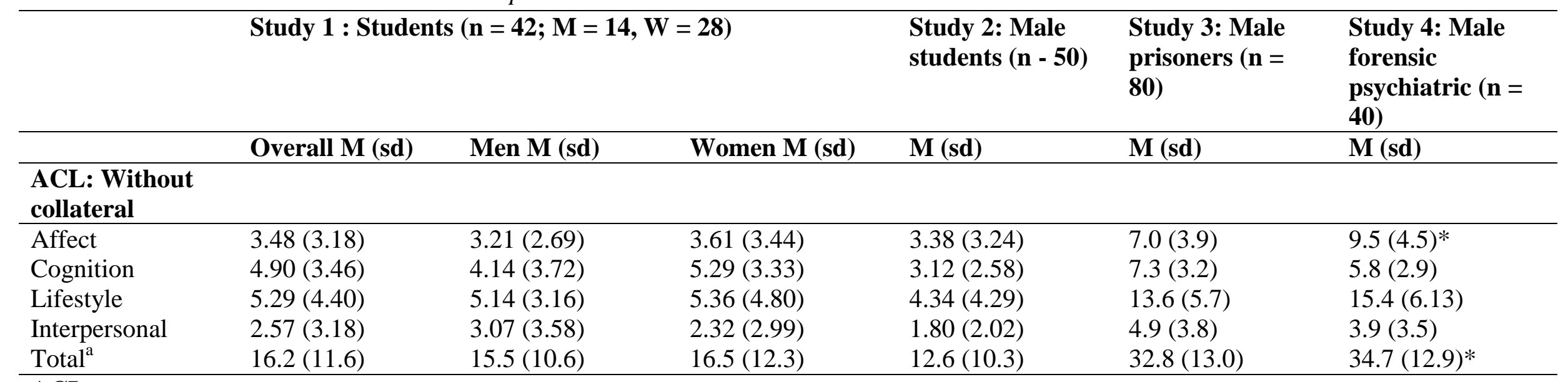

\section{ACL: \\ Incorporating \\ collateral}

\begin{tabular}{|c|c|c|c|c|c|c|}
\hline Affect & - & - & - & - & $11.9(6.5)$ & $12.8(3.9)^{*}$ \\
\hline Cognition & - & - & - & - & $12.3(5.7)$ & $10.6(3.7)$ \\
\hline Lifestyle & - & - & - & - & $24.3(9.9)$ & $21.9(5.5)$ \\
\hline Interpersonal & - & - & - & - & $5.4(4.11)$ & $5.1(3.5)$ \\
\hline Total & - & - & - & - & $53.9(21.3)$ & $50.3(13.3)^{*}$ \\
\hline \multicolumn{7}{|l|}{ PCL-SV } \\
\hline PCL-SV Total & - & - & - & $2.38(2.72)$ & - & $14.6(4.3)$ \\
\hline PCL-SV Factor 1 & - & - & - & $1.14(2.01)$ & - & $6.35(2.7)$ \\
\hline PCL-SV Factor 2 & - & - & - & $1.24(1.33)$ & - & $8.3(2.7)$ \\
\hline
\end{tabular}

$*_{\mathrm{n}}=38,2 \mathrm{msg}$

a one way ANOVA was conducted across the ACL total mean across samples, using post hoc Scheffé. There was an overall effect (F(72.2), df $=3, \mathrm{~F}=.0001$; with the student samples each presenting with lower ACL totals than both forensic samples, with forensic psychiatric (study 4) presenting with a higher score than the prisoner sample (study 3 ). 
Table 3.

Implicit components of the ACL and association with PCL-SV

\begin{tabular}{|c|c|c|c|c|c|c|c|c|c|c|}
\hline \multirow{2}{*}{$\begin{array}{l}\text { ACL Implicit } \\
\text { Component }\end{array}$} & \multirow{2}{*}{$\begin{array}{l}\text { Study } 2 \\
\text { Students } \\
(\mathrm{n}=50)\end{array}$} & \multirow{2}{*}{$\begin{array}{l}\text { Study } 4 \\
\text { Forensic } \\
\text { Psychiatric } \\
(\mathrm{n}=40) \\
\mathrm{M}(\mathrm{sd})\end{array}$} & \multicolumn{4}{|c|}{ Study 2: Male Students } & \multicolumn{4}{|c|}{ Study 4: Male Forensic Psychiatric } \\
\hline & & & Correlatio & & & & Correlatic & & & \\
\hline $\begin{array}{l}\text { Identifying } \\
\text { emotions }\end{array}$ & & & $\begin{array}{l}\text { Total } \\
\text { PCL-SV }\end{array}$ & $\begin{array}{l}\text { PCL-SV } \\
\text { F1 }\end{array}$ & $\begin{array}{l}\text { PCL-SV } \\
\text { F2 }\end{array}$ & $\begin{array}{l}\text { Total } \\
\text { ACL }\end{array}$ & $\begin{array}{l}\text { Total } \\
\text { PCL-SV }\end{array}$ & $\begin{array}{l}\text { PCL-SV } \\
\text { F1 }\end{array}$ & $\begin{array}{l}\text { PCL-SV } \\
\text { F2 }\end{array}$ & $\begin{array}{l}\text { Total } \\
\text { ACL }\end{array}$ \\
\hline $\begin{array}{l}\text { Number of } \\
\text { emotional words } \\
\text { correctly identified }\end{array}$ & $19.8(2.4)$ & $22.4(18.1)$ & $-.32 * *$ & $-.44 * * * *$ & .01 & $-.27^{\mathrm{b}}$ & .16 & .06 & .19 & -.11 \\
\hline $\begin{array}{l}\text { Response time } \\
\text { (seconds) }\end{array}$ & $\begin{array}{l}94.3 \\
(35.9)\end{array}$ & $\begin{array}{l}115.83 \\
(51.8)\end{array}$ & .08 & .02 & .15 & -.04 & $.37 * *$ & $-.47 * * * *$ & -.12 & -.23 \\
\hline \multicolumn{11}{|l|}{ Feeling emotions } \\
\hline $\begin{array}{l}\text { Number correctly } \\
\text { ranked emotional } \\
\text { scenarios }\end{array}$ & $6.9(.51)$ & $9.6(20.8)$ & .15 & .11 & .13 & .08 & .16 & .03 & .22 & -.09 \\
\hline $\begin{array}{l}\text { Response time } \\
\text { (seconds) }\end{array}$ & $\begin{array}{l}215.1 \\
(70,2)\end{array}$ & $\begin{array}{l}268.6 \\
(144.9)\end{array}$ & -.06 & .02 & .18 & -.08 & -.26 & -.20 & -.21 & $-.32 *$ \\
\hline $\begin{array}{l}\text { Emotion produced in } \\
\text { self }\end{array}$ & $25.1(5.0)$ & $27.9(13.7)$ & $-.42 * * *$ & $-.46^{* * * * *}$ & -.17 & $-.40 * * *$ & -.04 & -.08 & .009 & .23 \\
\hline $\begin{array}{l}\text { Emotion thought } \\
\text { produced in others }\end{array}$ & $28.6(2.9)$ & $28.1(13.2)$ & -.13 & -.08 & -.15 & -.25 & .11 & .04 & .13 & .04 \\
\hline
\end{tabular}




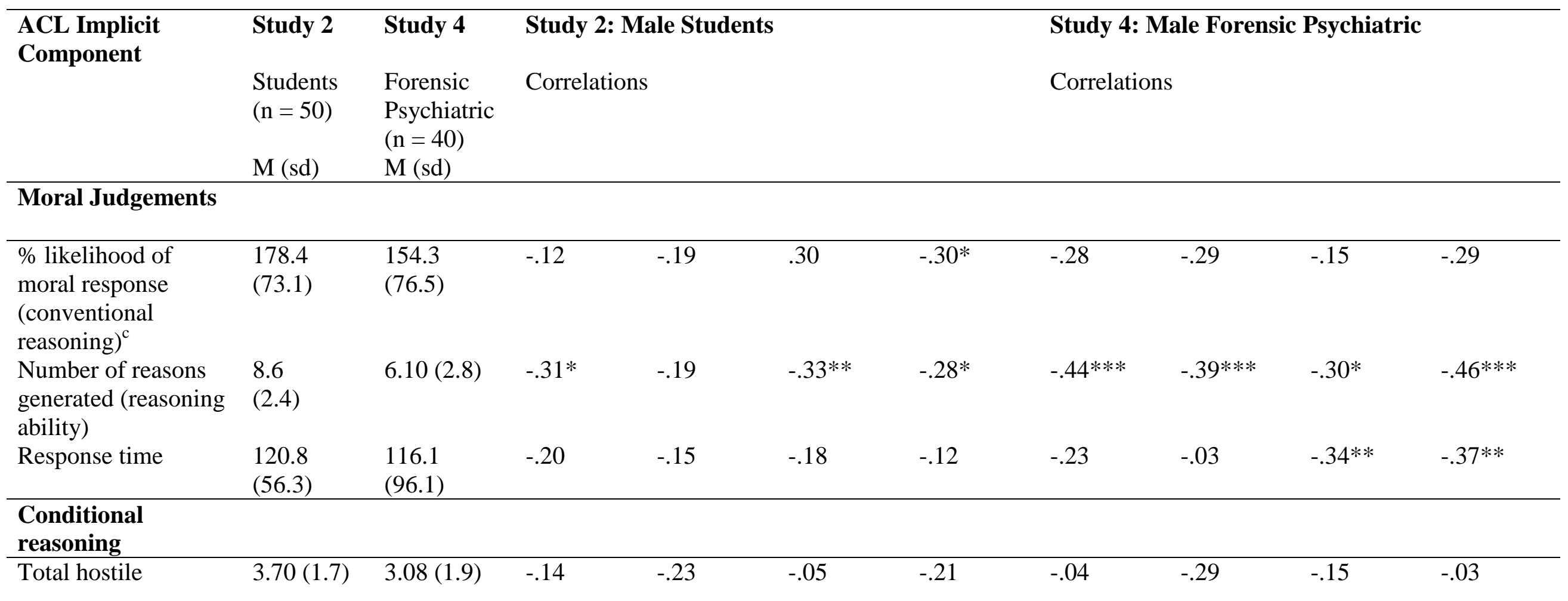

The ACL implicit tests presented here were independent of the total ACL score which was a rating given on a scale of 0 to $3{ }^{b} .06 ;{ }^{*} p<.05 ;{ }^{* *} p<.02 ;{ }^{* * * *} p<.01 ; * * * * p<.001$;

${ }^{\mathrm{c}}$ Asked to rate each scenario out of $100 \%$ and thus $\%$ can be higher than 100 . 